\title{
CFD study of Convective Heat Transfer of Water Flow Through Micro-Pipe with Mixed Constant Wall Temperature and Heat Flux Wall Boundary Conditions
}

\author{
Amjad Ali Pasha ${ }^{1,}{ }^{,}$, Meshal Nuwaym Al-Harbi ${ }^{2}$, Surfarazhussain S. Halkarni ${ }^{3}$, Nazrul Islam², D. Siva \\ Krishna Reddy ${ }^{4}$, S. Nadaraja Pillai ${ }^{5}$, Ufaith Qadiri ${ }^{6}$
}

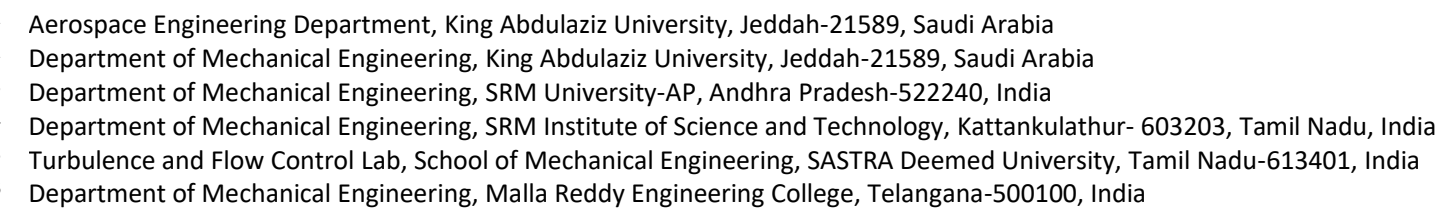

\section{Article history:}

Received 15 April 2021

Received in revised form 2 June 2021

Accepted 3 June 2021

Available online 21 July 2021

\begin{abstract}
The dissipation of heat in tiny engineering systems can be achieved with fluid flow through micro pipes. They have the advantage of less volume to large surface ratio convective heat transfer. There are deep-rooted analytical relations for convective heat transfer available for fluid flow through macro size pipes. But differences exist between the convective heat transfer for fluid flow through macro and micro pipes. Therefore, there is a good scope of work in micro convection heat transfer to study the mechanism of fundamental flow physics. There have been studies with either constant heat flux wall boundary conditions or constant wall temperature boundary conditions with constant and variable property flows. In this article, first, the numerical simulations are validated with the experimental data for $2 \mathrm{D}$ axisymmetric conventional pipe with pipe diameter of $8 \mathrm{~mm}$ is taken with laminar, steady, and single-phase water flows with constant wall heat flux boundary condition of $1 \mathrm{~W} / \mathrm{cm}^{2}$. The computed Nusselt number is compared to the experimental results at different Reynolds numbers of 1350, 1600 and 1700 . In the next study, three-dimensional micropipe laminar flow is studied numerically using water with an inlet velocity of $3 \mathrm{~m} / \mathrm{s}$ and pipe diameter of $100 \mu \mathrm{m}$. The mixed wall boundary conditions with upper half pipe surface subjecting to constant wall temperature of $313 \mathrm{~K}$ and lower half surface subjecting to $100 \mathrm{~W} / \mathrm{cm}^{2}$ are used in the simulations. The focus of research would be to consider the effect of temperature-dependent properties like thermal conductivity, viscosity, specific heat, and density (a combined effect we call it as variable properties) on micro-pipe flow characteristics like Nusselt number at mixed wall boundary conditions and compare it with the constant property flows. The conventional pipe showed no significant difference with variable and constant property flows with different Reynolds numbers. On contrary the flow through 3D micropipe shows that the Nusselt number with variable property flows is less as compared to the constant property flows.
\end{abstract}

\section{Keywords:}

Convective heat-transfer; Laminar flow; Micro-pipe; Nusselt number; Pressure drop; Variable fluid properties

\footnotetext{
* Corresponding author.

E-mail address: aapasha@kau.edu.sa (Amjad Ali Pasha)
} 


\section{Introduction}

The miniature modern machines in medical, chemical and information technology demand highly effective and space-efficient heat exchanging devices. The heat transfer and hydrodynamic features of micro ducts have been investigated enormously in past few years by following researchers: Gulhane and Mahulikar [1], Mala et al., [2], Sobhan and Garimella [3], Morini [4], Hetsroni et al., [5], Kandlikar and Steinke [6], Hong and Asako [7], van Rij et al., [8], Kandlikar [9], Garimella and Sobhan [10], Prabhu and Mahulikar [11], Adham et al., [12], Dixit and Ghosh [13], Rastogi and Mahulikar [14], Tharkar and Mahulikar [15], Tharkar and Mahulikar [16] and Kumar et al., [17]. There are still great variations in the reported data. Alterations exist in many aspects: drag of fluid in laminar, transit and turbulent single-phase flows, heat exchange of fluids, two-phase adiabatic and heated microchannels. These contexts have difficulties linking to channel shape, aspect ratio, type of fluid, compressibility, phase, surface irregularities and heat transfer circumstances in micro pipes. Different cross sections like triangular and rectangular shapes were taken to study the performance of the hybrid micro-channel flows $[18,19]$. The traditional heat transport theory tells when the cross-section of channels reduces, the coefficient of heat transfer surges for fully developed fluid flow [20]. Hence, small-sized ducts are selected to get higher values of heat transfer. For instance, these micro conduits are employed to bring about heat loss in Large-Scale Integration (LSI) chips and micro total chemical analyzing system micro Total Analysis System ( $\mu$-TAS), micro electrical-mechanical systems (MEMS) $[21,22]$.

The liquid flow through micro ducts is used to dissipate heat in miniature engineering systems, which is of paramount importance for their performance. Fluid flow, through conventional macro size ducts, has been extensively studied to develop the well-established analytical relations of heat transfer $[5,23,24]$. Unfortunately, there exist many discrepancies between the mechanism of fluid flow and heat transfer in macro ducts and micro ducts. This opens a broad door to unveil the flow physics in micro convection heat transfer. The first micro-channel experimental studies performed by Tuckerman and Pease [25], they have demonstrated that a greater heat transfer rate could be achieved with smaller diameters. Subsequently, several investigations have been conducted over the past years to practically analyze the flow through micro-channels [26-29]. However, experimental measurements for micro-channel pipes face a major challenge to date. As an alternative, numerical simulations have been employed by researchers, to overcome this limitation $[1,30]$.

Generally, constant properties $\left(C_{P}\right)$ are assumed in fluid flow and heat transfer analytical calculations for duct flows. The effect of fluid property variations with temperature such as density dependent on temperature $\rho(T)$, thermal conductivity dependent on temperature $k(T)$, specific heat at constant pressure $C_{P}(T)$ and viscosity dependent on temperature $\mu(T)$ are generally neglected that account for large temperature differences when compared with constant properties. It is found that there are around 30\% deviations in Nusselt number ( $\mathrm{Nu}$ ) [31-34]. Experimental shreds of evidence, with a comprehensive review of literature, were provided by Kandlikar and Steinke [6] showing the discrepancies present in literature for frictional factor and pressure drop for flows through microchannels. After reviewing of the pertinent literature, it is found that there are suitable discrepancies in the behavior of thermophysical properties as a function of temperature in the micropipe flows with convection.

There are also discrepancies in the comparison with experimental data in pressure drop and heat transfer in micro pipe flows. Hence, there is a need for appropriate modelling of thermophysical properties $\left[\rho(T), k(T), C_{P}(T)\right.$ and viscosity $\left.\mu(T)\right]$ as a function of temperature and their incorporation in the real life applications with the aid of computational results leading to safer designs. The focus of the current work is to investigate the effects of the temperature variation of thermophysical 
properties on heat transfer and hydrodynamic characteristics of 3D micropipe with mixed wall boundary conditions. Also, the mixed wall boundary conditions are not studied till date. The objective of the present study is to compute numerically three-dimensional incompressible, steady, laminar flow through micro pipe to investigate the effect of temperature-dependent thermophysical properties on hydrodynamic and heat transfer characteristics at combined constant wall heat flux and constant wall temperature boundary condition. So, as a fundamental fluid dynamic it would be interesting to study the behaviour of heat transfer characteristics i.e., Nu, for developing water flow through the micro pipe with constant wall temperature at top half and constant heat flux applied and bottom half surfaces of a three dimensional (3D) cylindrical pipe. The water is chosen and used as the working fluid in the present computations.

The paper is organized as follows. First, the simulation methodology is discussed. In this section, governing equations, geometry details, grid convergence study, numerical method and formulas are discussed. Next, the CFD validation is performed for conventional pipe flow with available experimental data by Heyhat et al., [35] for the constant property (CP) flows and variable property (VP) flows. Also, the effect of inlet Reynolds number on Nusselt number, skin friction and pressure drop are studied. Next, the 3D cylindrical pipe CFD analysis is done with constant property (CP) flows and variable property (VP) flows. Finally, the conclusions are discussed.

\section{Numerical Methodology}

The 3D form of governing equations in steady-state form for incompressible flows in cylindrical coordinates $(r, \theta, z)$ are given by Eq. (1)-(5) [36].

Balance of mass:

$\frac{1}{\mathrm{r}} \frac{\partial\left(\mathrm{ru}_{\mathrm{r}}\right)}{\partial \mathrm{r}}+\frac{1}{\mathrm{r}} \frac{\partial\left(\mathrm{ru}_{\theta}\right)}{\partial \theta}+\frac{\partial \mathrm{u}_{\mathrm{z}}}{\partial \mathrm{z}}=0$

Balance of momentum:

$$
\begin{aligned}
& \rho\left(\frac{\partial \mathrm{u}_{\mathrm{r}}}{\partial \mathrm{r}}+\frac{\mathrm{u}_{\theta}}{\mathrm{r}} \frac{\partial \mathrm{u}_{\mathrm{r}}}{\partial \theta}-\frac{\mathrm{u}_{\theta}^{2}}{\mathrm{r}}+\mathrm{u}_{\mathrm{z}} \frac{\partial \mathrm{u}_{\mathrm{r}}}{\partial \mathrm{z}}\right)=-\frac{\partial \mathrm{p}}{\partial \mathrm{r}}+\mu\left(\frac{\partial}{\partial \mathrm{r}}\left(\frac{1}{\mathrm{r}} \frac{\partial}{\partial \mathrm{r}}\left(\mathrm{ru}_{\mathrm{r}}\right)\right)+\frac{1}{\mathrm{r}^{2}} \frac{\partial^{2} \mathrm{u}_{\mathrm{r}}}{\partial \theta^{2}}-\frac{2}{\mathrm{r}^{2}} \frac{\partial \mathrm{u}_{\theta}}{\partial \theta}+\frac{\partial^{2} \mathrm{u}_{\mathrm{r}}}{\partial \mathrm{z}^{2}}\right) \\
& \rho\left(\frac{\partial \mathrm{u}_{\theta}}{\partial \mathrm{r}}+\frac{\mathrm{u}_{\theta}}{\mathrm{r}} \frac{\partial \mathrm{u}_{\theta}}{\partial \theta}+\frac{\mathrm{u}_{\mathrm{r}} \mathrm{u}_{\theta}}{\mathrm{r}}+\mathrm{u}_{\mathrm{z}} \frac{\partial \mathrm{u}_{\theta}}{\partial \mathrm{z}}\right)=-\frac{1}{\mathrm{r}} \frac{\partial \mathrm{p}}{\partial \theta}+\mu\left(\frac{\partial}{\partial \mathrm{r}}\left(\frac{1}{\mathrm{r}} \frac{\partial}{\partial \mathrm{r}}\left(\mathrm{ru}_{\theta}\right)\right)+\frac{1}{\mathrm{r}^{2}} \frac{\partial^{2} \mathrm{u}_{\theta}}{\partial \theta^{2}}+\frac{2}{\mathrm{r}^{2}} \frac{\partial \mathrm{u}_{\mathrm{r}}}{\partial \theta}+\frac{\partial^{2} \mathrm{u}_{\theta}}{\partial \mathrm{z}^{2}}\right) \\
& \left.\rho\left(\frac{\partial \mathrm{u}_{\mathrm{z}}}{\partial \mathrm{r}}+\frac{\mathrm{u}_{\theta}}{\mathrm{r}} \frac{\partial \mathrm{u}_{\mathrm{z}}}{\partial \theta}+\mathrm{u}_{\mathrm{z}} \frac{\partial \mathrm{u}_{\mathrm{z}}}{\partial \mathrm{z}}\right)=-\frac{\partial \mathrm{p}}{\partial \mathrm{z}}+\mu\left(\frac{1}{\mathrm{r}} \frac{\partial}{\partial \mathrm{r}}\left(\mathrm{r} \frac{\partial \mathrm{u}_{\mathrm{z}}}{\partial \mathrm{r}}\right)\right)+\frac{1}{\mathrm{r}^{2}} \frac{\partial^{2} \mathrm{u}_{\mathrm{z}}}{\partial \theta^{2}}+\frac{\partial^{2} \mathrm{u}_{\mathrm{z}}}{\partial \mathrm{z}^{2}}\right)
\end{aligned}
$$

Balance of energy:

$$
\begin{gathered}
\rho \mathrm{C}_{\mathrm{p}}\left(\mathrm{u}_{\mathrm{r}} \frac{\partial \mathrm{T}}{\partial \mathrm{r}}+\frac{\mathrm{u}_{\theta}}{\mathrm{r}} \frac{\partial \mathrm{T}}{\partial \theta}+\mathrm{u}_{\mathrm{z}} \frac{\partial \mathrm{T}}{\partial \mathrm{z}}\right)=\mathrm{k}\left[\frac{1}{\mathrm{r}} \frac{\partial}{\partial \mathrm{r}}\left(\mathrm{r} \frac{\partial \mathrm{T}}{\partial \mathrm{r}}\right)+\frac{1}{\mathrm{r}^{2}} \frac{\partial^{2} \mathrm{~T}}{\partial \theta^{2}}+\frac{\partial^{2} \mathrm{~T}}{\partial \mathrm{z}^{2}}\right]+ \\
2 \mu\left\{\left(\frac{\partial \mathrm{u}_{\mathrm{r}}}{\partial \mathrm{r}}\right)^{2}+\left[\frac{1}{\mathrm{r}}\left(\frac{\partial \mathrm{u}_{\theta}}{\partial \theta}+\mathrm{u}_{\mathrm{r}}\right)\right]^{2}+\left(\frac{\partial \mathrm{u}_{\mathrm{z}}}{\partial \mathrm{z}}\right)^{2}\right\}+\mu\left\{\left(\frac{\partial \mathrm{u}_{\theta}}{\partial \mathrm{z}}+\frac{1}{\mathrm{r}} \frac{\partial \mathrm{u}_{\mathrm{z}}}{\partial \theta}\right)^{2}+\left(\frac{\partial \mathrm{u}_{\mathrm{z}}}{\partial \mathrm{r}}+\frac{\partial \mathrm{u}_{\mathrm{r}}}{\partial \mathrm{z}}\right)^{2}+\left[\frac{1}{\mathrm{r}} \frac{\partial \mathrm{u}_{\mathrm{r}}}{\partial \theta}+\mathrm{r} \frac{\partial}{\partial \mathrm{r}}\left(\frac{\mathrm{u}_{\theta}}{\mathrm{r}}\right)\right]^{2}\right\}
\end{gathered}
$$




\subsection{Modelling of Thermo Physical Properties for Water}

These polynomial functions of thermophysical properties are used in our numerical simulations. The variation of thermophysical properties is shown in Figure 1. It shows that $\rho(T)$ and $\mu(T)$ decreases $k(T)$ increases whereas $C_{p}(T)$ decreases up to $310 \mathrm{~K}$ and increases beyond it, up to $373.15 \mathrm{~K}$, with increasing temperature. The modeling of thermophysical properties as a function of temperature is given by,

$$
\begin{aligned}
& \rho(T)=765.33+1.8142(T)-0.0035(T)^{2} \\
& C_{p}(T)=1.095 e^{4}-59.27(T)+0.171(T)^{2}-0.0001623(T)^{3} \\
& k(T)=-0.5752+6.3967 \times 10^{-3}(T)-8.151 \times 10^{-6}(T)^{2} \\
& \mu(T)=9.67 \times 10^{-2}-8.207 \times 10^{-4}(T)+2.344 \times 10^{-6}(T)^{2}-2.244 \times 10^{-9}(T)^{3}
\end{aligned}
$$

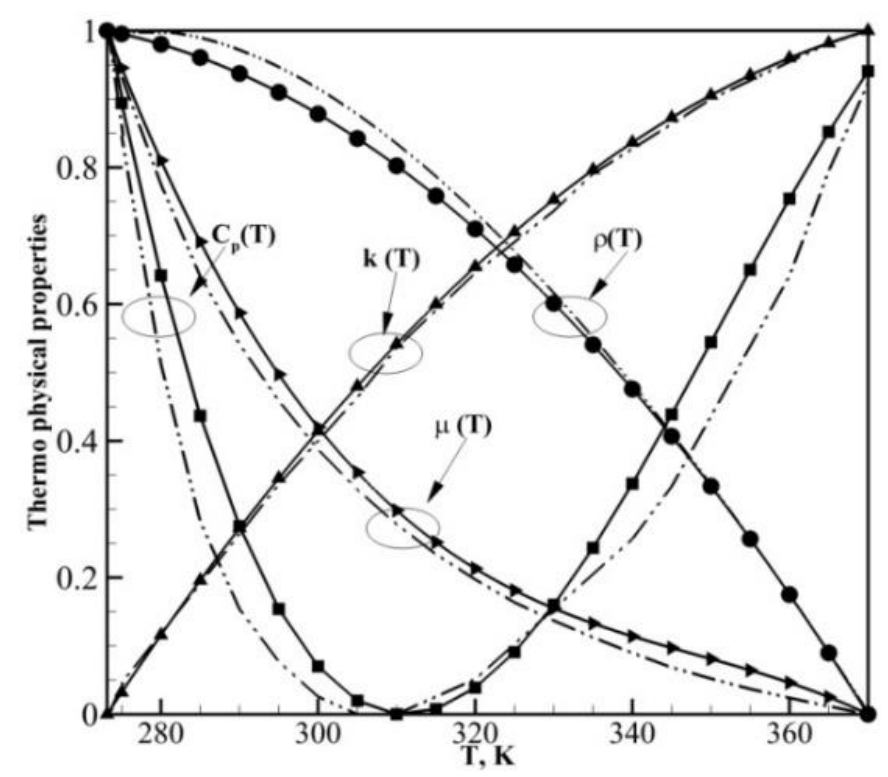

Fig. 1. Assessment of property polynomial functions to the physical data with the variation of temperature for water [37]

\subsection{CFD Validation with Experiments}

The grid is generated using the Pointwise package and the ANSYS-Fluent package 19.3 is used to carry out the numerical simulations. The post-processing is done using the Tecplot package. The governing equations are discretized using the second-order finite volume technique. The SIMPLE scheme is used to couple the velocity and pressure variables. The implicit method is used to reach the steady-state solutions. The no-slip velocity and uniformly distributed constant heat flux ( $\left.q_{w}\right)$ boundary conditions are used at the wall. The velocity inlet boundary conditions are given in Table 1. Atmospheric pressure is assigned at the outlet of pipe, $p_{\text {out }}=1.01325 \times 10^{5} \mathrm{~Pa}$. An axisymmetric boundary condition i.e., gradients in an axial direction, $\partial(p) / \partial z, \partial(T) / \partial z$ and $\partial(\rho) / \partial z$ are assumed to be zero at the centerline axis. 
Table 1

Geometry and boundary conditions for different test cases

\begin{tabular}{ll}
\hline Parameters & Conditions \\
\hline Pipe diameter $(D), m$ & 0.008 \\
Inlet temperature $\left(\mathrm{T}_{\text {in }}\right), \mathrm{K}$ & 283 \\
Inlet velocities $\left(\mathrm{u}_{\text {in }}\right), \mathrm{ms}^{-1}$ & $0.02784,0.0262,0.0221$ \\
Reynolds number $(\mathrm{Re})$ & $1700,1600,1350$ \\
Heat Flux $\left(\mathrm{q}_{\mathrm{w}}\right), \mathrm{W} / \mathrm{m}^{2}$ & 10610 \\
\hline
\end{tabular}

The Nusselt number for constant properties ( $\mathrm{Nu}_{\mathrm{CP}}$ ) and variable properties (Nuvp) for constant wall heat flux (CHF) are numerically calculated by Eq. (10) and Eq. (11),

$$
\begin{aligned}
& \mathrm{Nu}_{\mathrm{CP}}=\frac{\mathrm{hD}}{\mathrm{k}_{\mathrm{CP}}}=\frac{\mathrm{q}_{\mathrm{w}} \mathrm{D}}{\mathrm{k}_{\mathrm{CP}}\left(\mathrm{T}_{\mathrm{w}}-\mathrm{T}_{\mathrm{m}}\right)_{\mathrm{CP}}} \\
& \mathrm{Nu}_{\mathrm{VP}}=\frac{\mathrm{hD}}{\mathrm{k}(\mathrm{T})}=\frac{\mathrm{q}_{\mathrm{w}} \mathrm{D}}{\mathrm{k}(\mathrm{T})\left(\mathrm{T}_{\mathrm{w}}-\mathrm{T}_{\mathrm{m}}\right)_{\mathrm{VP}}}
\end{aligned}
$$

Here, $(h)$ denotes the heat transfer coefficient, the $\left(q_{w}\right)$ is constant wall heat flux.

In the numerical simulations, the conventional pipe length (L) of $1.5 \mathrm{~m}$ and its diameter (D) as $0.008 \mathrm{~m}$. The mesh is exponentially stretched in the radial direction from the wall and the first cell near the wall is taken as $5 \times 10^{-6} \mathrm{~m}$. The grid is also exponentially stretched in the z-direction with many grid points at the entrance region to capture high gradients of the developing flow. The grid convergence analysis is done in detail.

\subsection{Grid Convergence Study}

Figure 2 shows that increase in number of grid points in the axial direction from 500 to 1000 (while keeping same number of grid points of 120 in radial direction) has minor effect on the $T_{m}, T_{w}$, $\mathrm{Nu}, \mathrm{P}$ and $\mathrm{C}_{\mathrm{f}}$ properties and hence $750 \times 120$ is taken as converged grid i.e., the solution does not change with further increase in number of grid points from 750 to 1000.

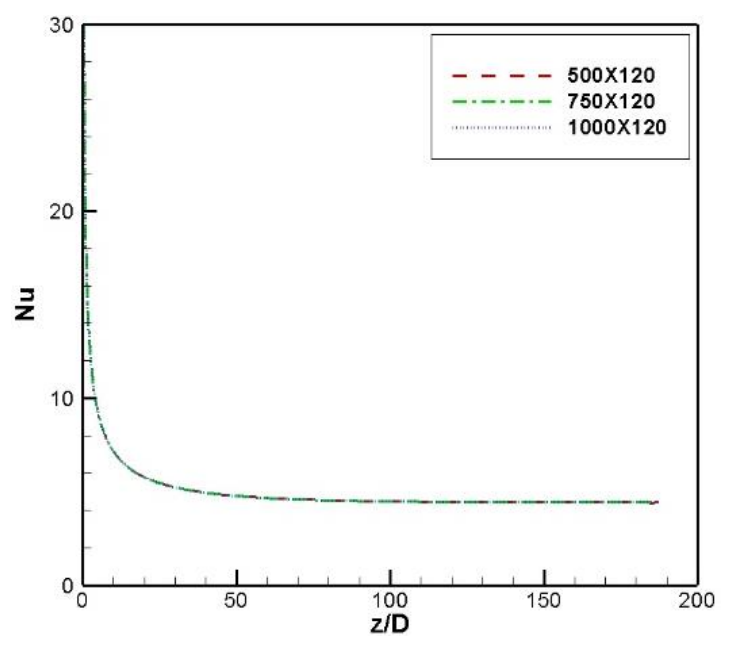

(a)

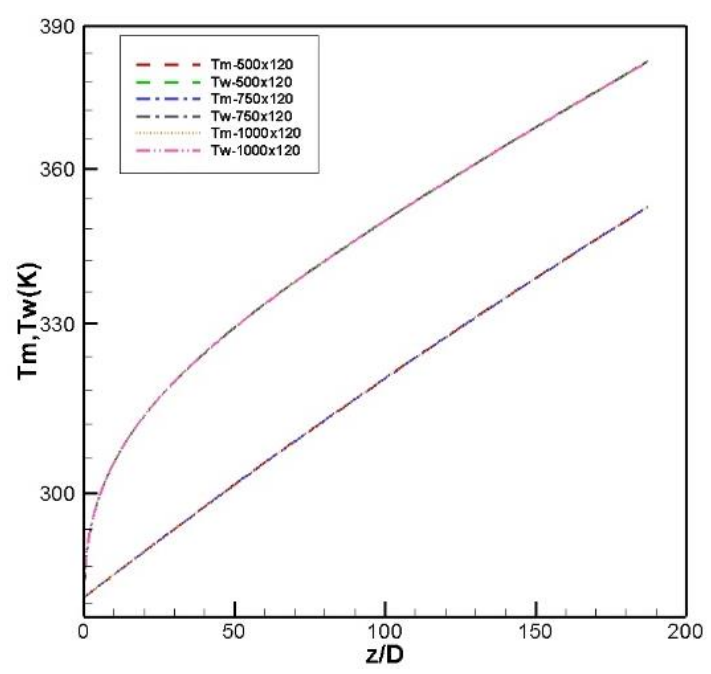

(b) 


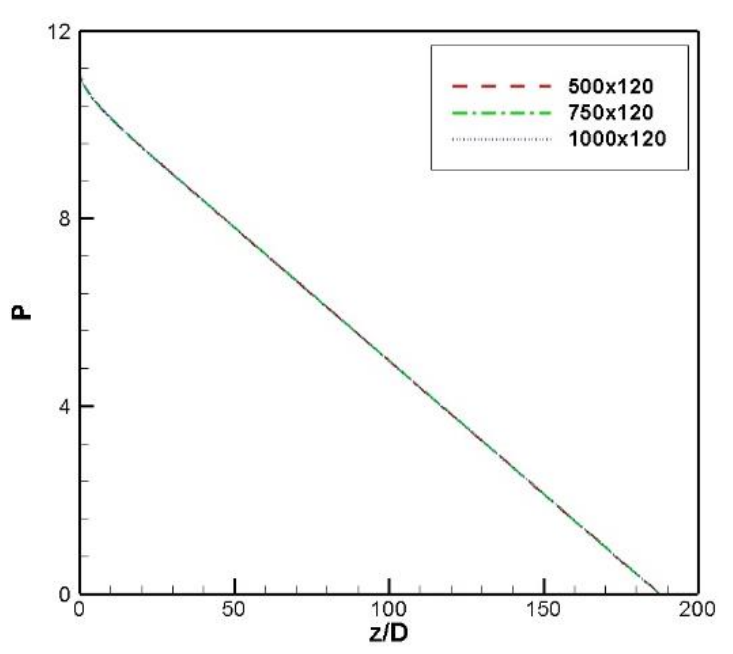

(c)

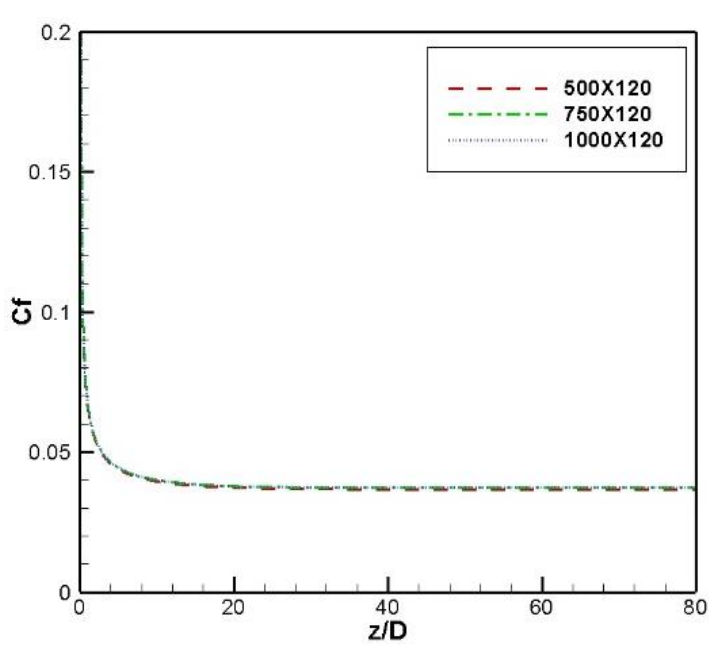

(d)

Fig. 2. Variation of (a) mean temperature $T_{m}$, wall temperature $T_{w}$ (b) Nusselt number (c) pressure and (d) skin friction with different grids of $500 \times 120,750 \times 120$ and $1000 \times 120$ with increase in number of points in the axial direction for $\mathrm{Re}=1700$ at constant wall heat flux $=10610 \mathrm{~W} / \mathrm{m}^{2}$

Figure 3 shows that that increasing the number of points in the radial direction from 50 to 100 and then to 120 (while keeping same number of grid points of 750 in the axial direction) has a small change in $T_{m}, T_{w}, N u, P$ and $C_{f}$. Therefore, 750 points in the axial direction and 100 points in the radial direction are sufficient to capture the velocity and temperature gradients. We conclude that the 750 $\times 100$ grid is taken as a converged grid i.e, the solution does not alter with further increase in both the axial and radial directions and hence this grid is used in two dimensional (2D) Computational Fluid Dynamics (CFD) calculations for conventional pipe.

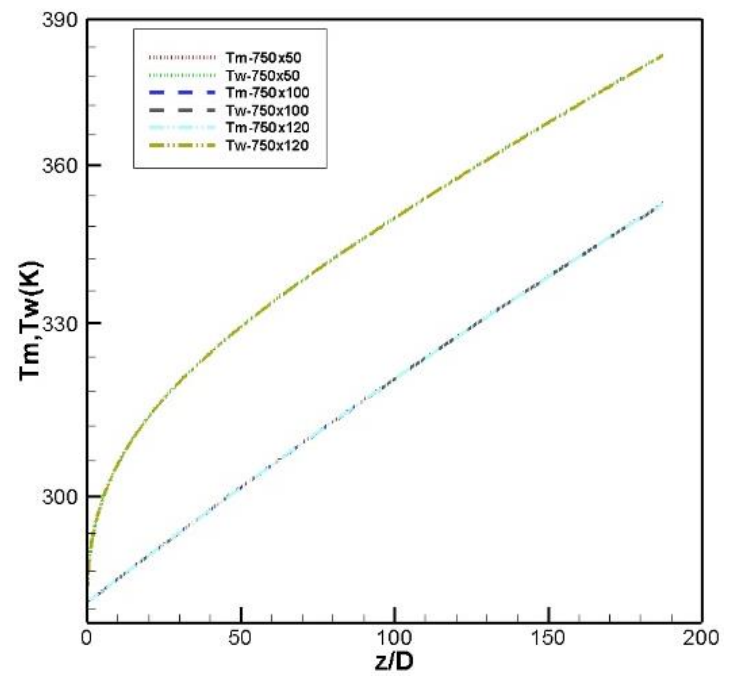

(a)

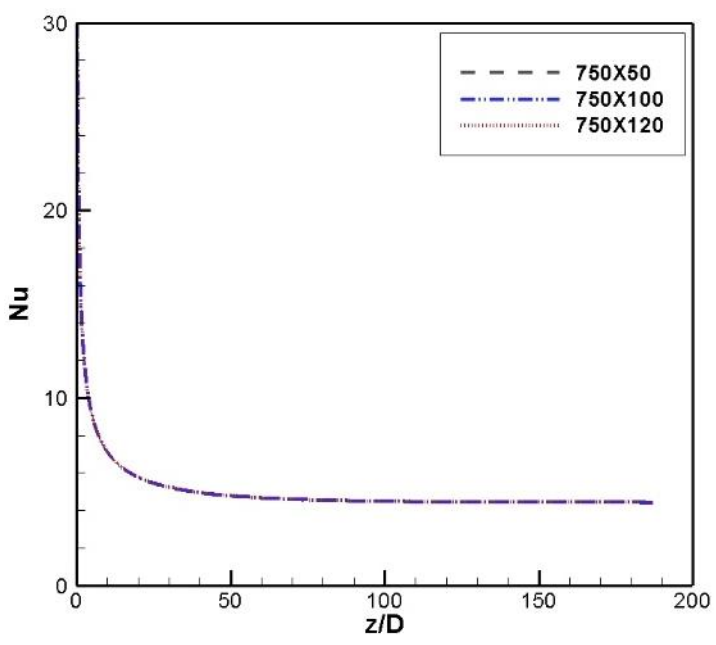

(b) 


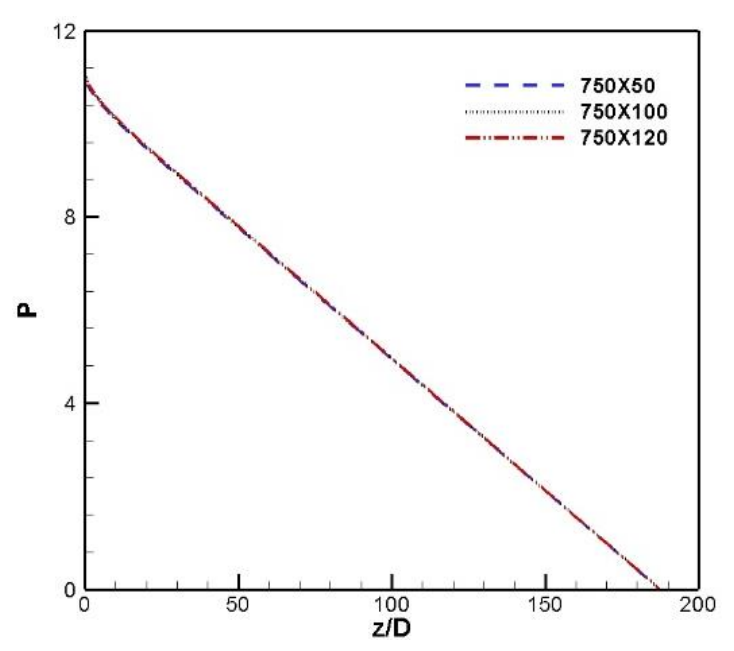

(c)

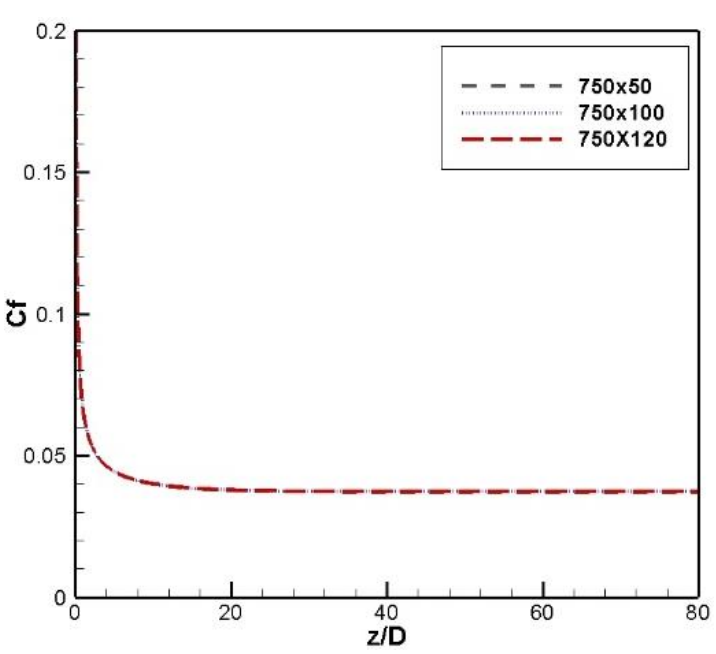

(d)

Fig. 3. Variation of (a) mean temperature $T_{m}$, wall temperature $T_{w}$, (b) Nusselt number (c) pressure and (d) skin friction with different grids of $750 \times 50,750 \times 100$ and $750 \times 120$ with increase in number of points in the radial direction for $\mathrm{Re}=1700$ at constant wall heat flux $=10610 \mathrm{~W} / \mathrm{m}^{2}$

Figure 4 shows that the variation of mean and wall temperatures with constant property flow with constant heat flux boundary condition for three Reynolds numbers of 1350, 1600 and 1700, a constant temperature difference $\left[\Delta T=\left(T_{w}-T_{m}\right)\right]$ is observed beyond $(z / d)=50$, therefore depicting thermally fully developed flow. The variation of Nusselt number along the axial direction under similar conditions of Reynolds number and constant wall heat flux is computed and compared with experimental data of Heyhat et al., [35] as shown in Figure 5. The variation of skin friction factor, $\mathrm{C}_{\mathrm{f}}$ along the walls of the micropipe is shown in Figure 6 shows that the $C_{f}$ decreases with an increase in the Reynolds number because of the corresponding increase in the boundary layer thickness.

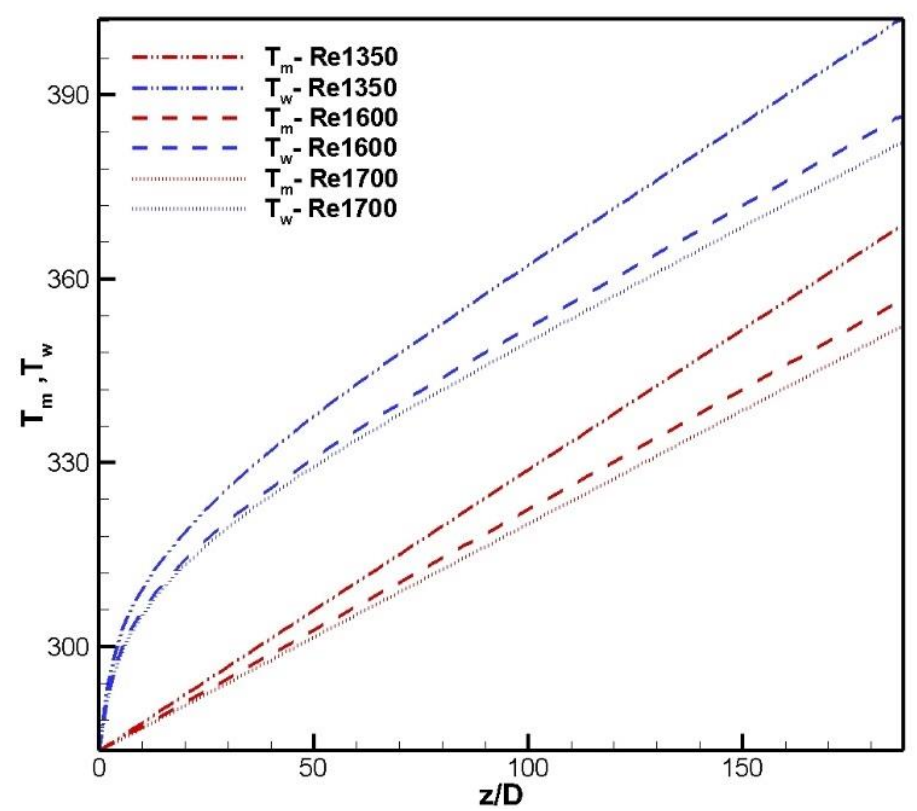

Fig. 4. Variation of mean temperature $\left(T_{m}\right)$ and wall temperature $\left(T_{w}\right)$ long the axial direction for the constant properties $\mathrm{CP}$ for $\mathrm{Re}=1350,1600$ and 1700 at constant wall heat flux $=10610 \mathrm{~W} / \mathrm{m}^{2}$ 


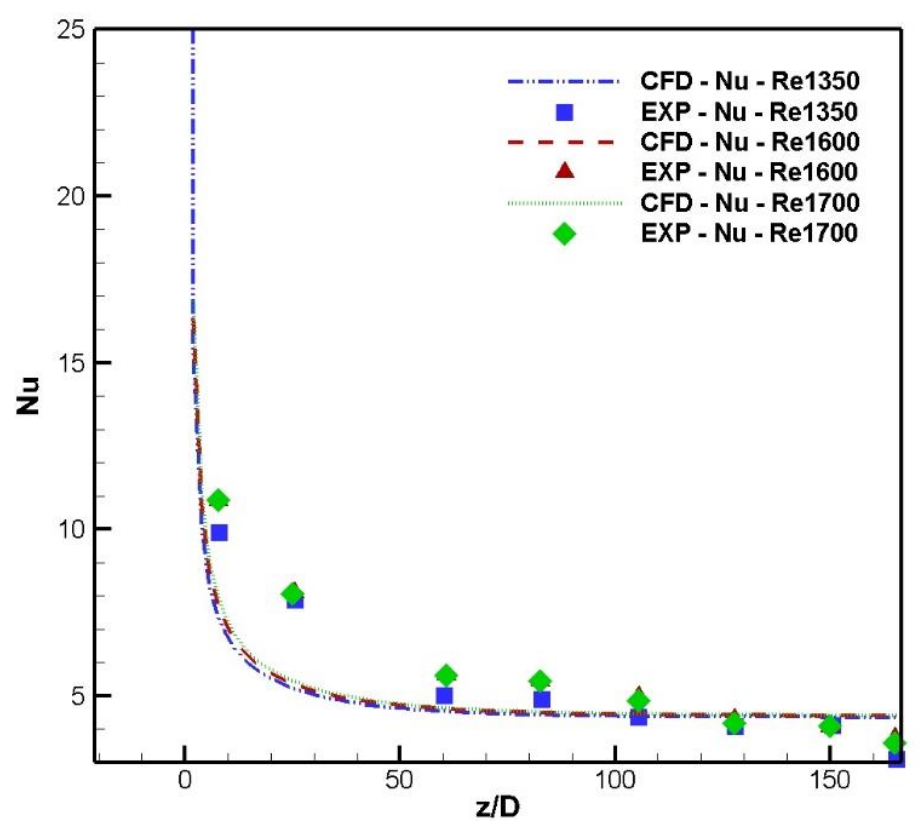

Fig. 5. Variation of Nusselt number along the axial direction for the constant properties $\mathrm{CP}$ for $\mathrm{Re}=1350,1600$ and 1700 at constant wall heat flux $=10610 \mathrm{~W} / \mathrm{m}^{2}$ compared to the experimental data by Heyhat et al., [35]

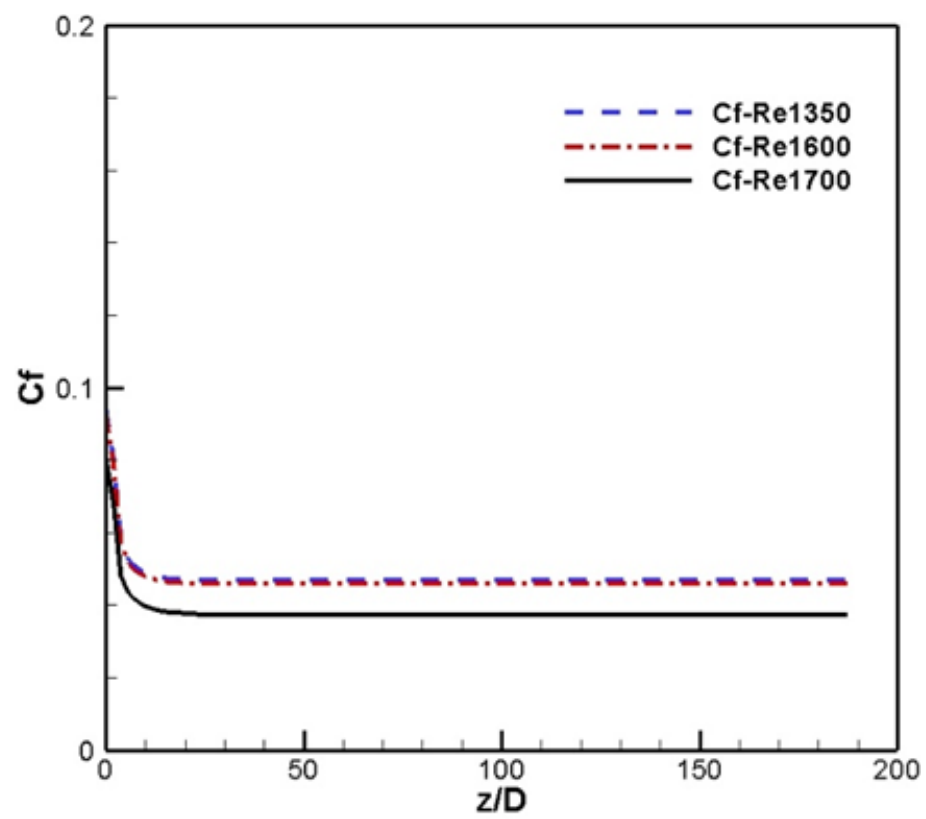

Fig. 6. Variation of skin friction $\left(C_{f}\right)$ along the wall for the constant properties $\mathrm{CP}$ for $\mathrm{Re}=1350,1600$ and 1700 at constant wall heat flux $q_{w}=10610 \mathrm{~W} / \mathrm{m}^{2}$

Figure 7 shows the variation of pressure along the micro-pipe walls for different Reynolds numbers and constant wall heat flux boundary conditions. The low Reynolds number has a lower pressure drop while the higher Reynolds number has a higher which is as per expectation. In the present work, we have validated our CFD simulation data with the corresponding experimental results. The comparison between CFD and experimental data for Nusselt number with Reynolds number is shown in Figure 8. There is an excellent agreement between the CFD simulation results 
and the experimental data. These small deviations may be attributed due to the uncertainty in the experimental measurements.

In case of macro-pipes, the simulation results show a peculiar variation between the mean bulk fluid temperatures and wall temperatures for variable properties shown in Figure 9(a). This may be attributed to the presence of strong thermal gradients which influence the thermophysical properties such as density $\rho(T)$, thermal conductivity $k(T)$, specific heat at constant pressure $C_{P}(T)$ and dynamic viscosity $\mu(T)$. The effect of variable properties on of Nusselt number is shown in Figure $9(b)$. The comparison of Nusselt number with non-dimensional length along the flow direction of macro-pipe reveals that overall, the influence of variable properties is not having a significant effect. But the effects of the thermal gradients near-wall influence the thermophysical properties in micro pipes. In the next section, these results are discussed.

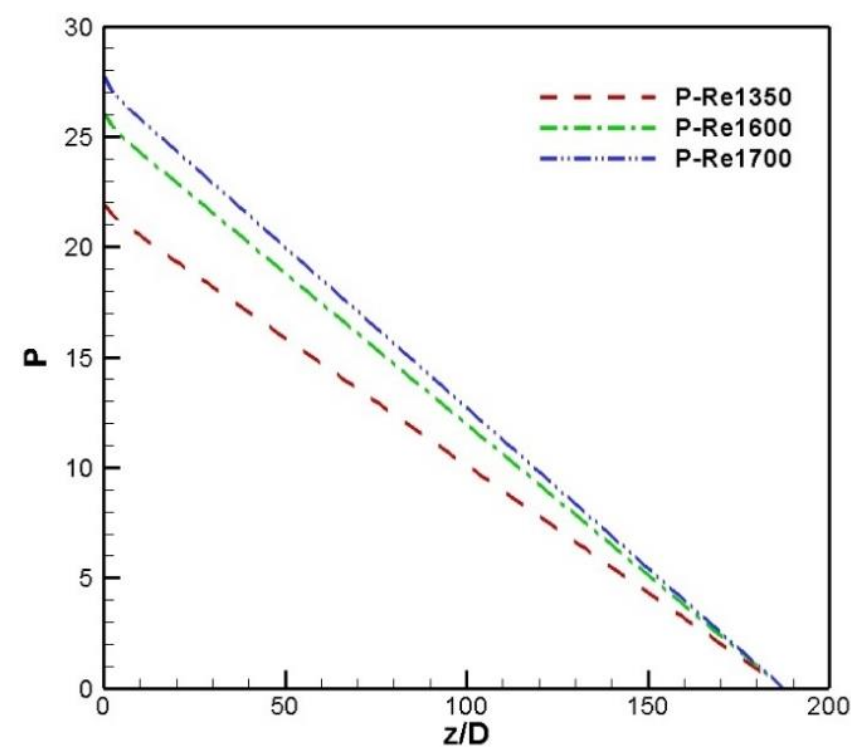

Fig. 7. Variation of wall pressure along the pipe with constant properties $\mathrm{CP}$ for $\mathrm{Re}=1350,1600$ and 1700 at constant wall heat flux $=10610 \mathrm{~W} / \mathrm{m}^{2}$

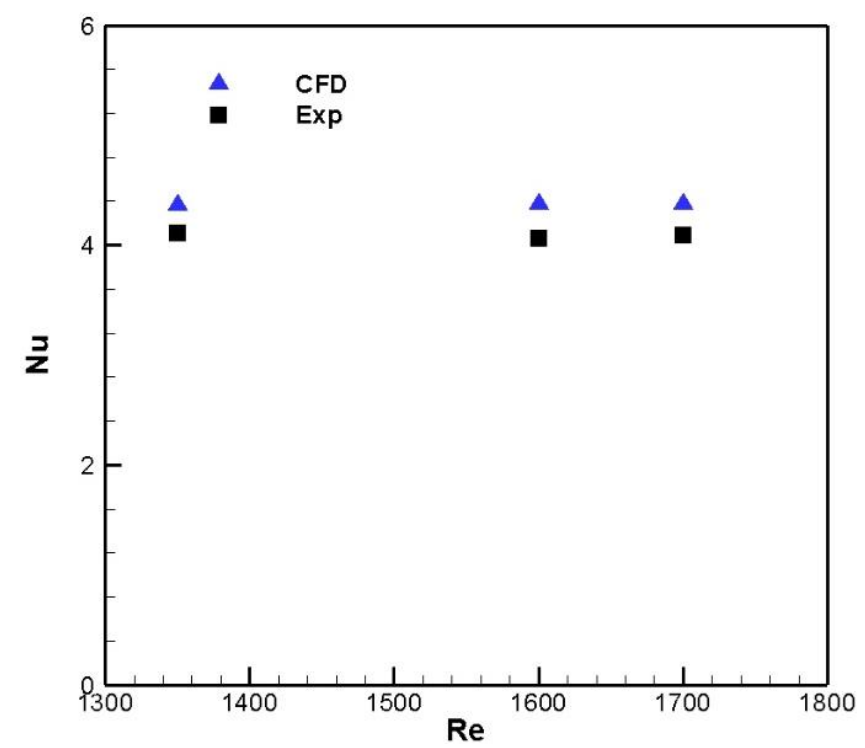

Fig. 8. Comparison of CFD and experimental data for variation of Nusselt number with Reynolds number 

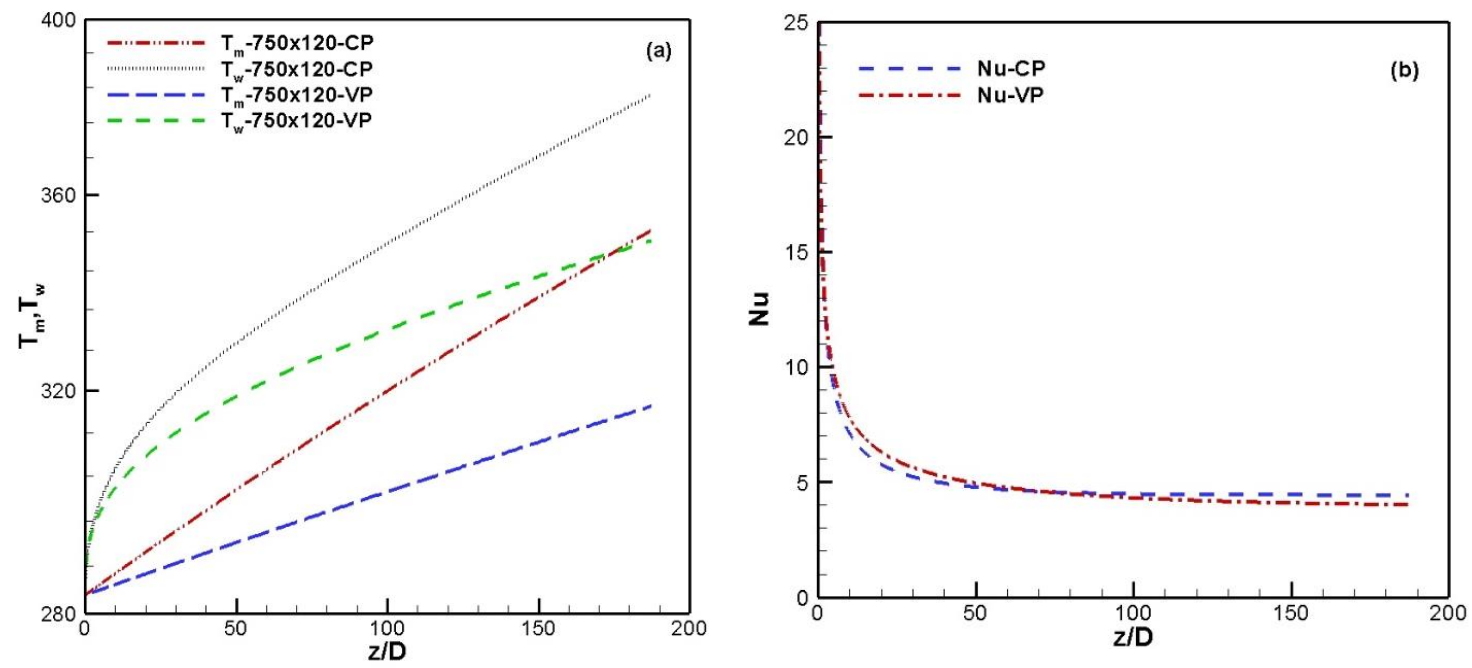

Fig. 9. Variation of (a) mean temperature $T_{m}$ and wall temperature $T_{w}$ and (b) Nusselt number with constant properties (CP) and variable properties (VP) for flow in a pipe (750 x120 grid points) with $\operatorname{Re}=1700$ at constant wall heat flux $=10610 \mathrm{~W} / \mathrm{m}^{2}$

\section{Results and Discussions}

In this section, we discuss the three-dimensional CFD results for micro-pipe water flow as shown in Figure 10 with an inlet velocity of $3 \mathrm{~ms}^{-1}$ and a pipe diameter of $100 \times 10^{-6} \mathrm{~m}$. The mixed wall boundary conditions are (a) upper half pipe - constant wall temperature $=313.15 \mathrm{~K}$ and (b) lower half pipe - constant heat flux $=100 \mathrm{~W} / \mathrm{cm}^{2}$.

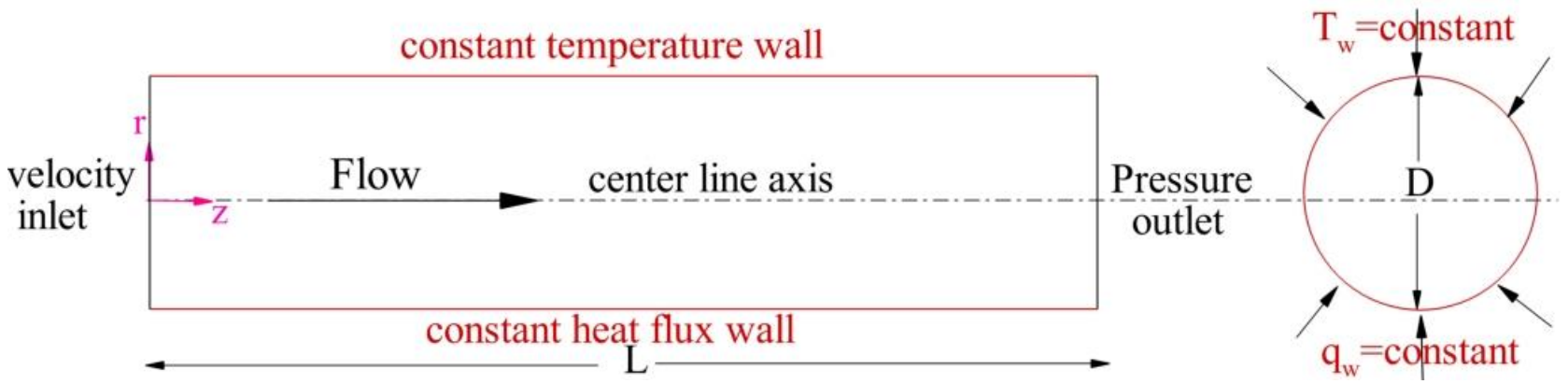

Fig. 10. Micropipe convective heat transfer flow with combined constant heat flux and constant wall temperature boundary condition

Figure 11 shows the 3D pipe mesh and its front view is also shown ( $\mathrm{H}$-topology grid). Care is taken to remove the singularity developed when we use rotate option in the grid generation package to generate the grid from a 2D rectangle to form a 3D pipe mesh. A grid converged solution is obtained on $300 \times 40 \times 40$ mesh with 300 points in the x-direction, 40 points in the y-direction and 40 points in the z-direction. 


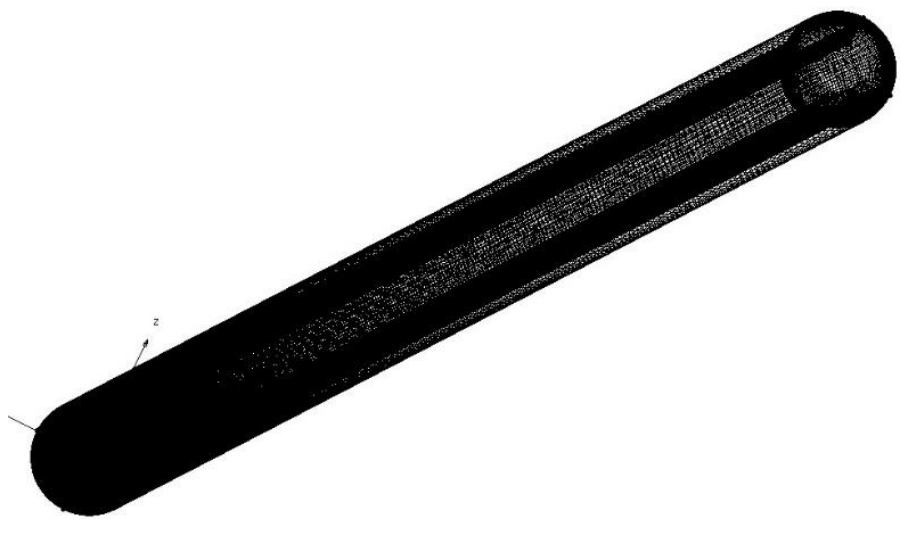

(a)

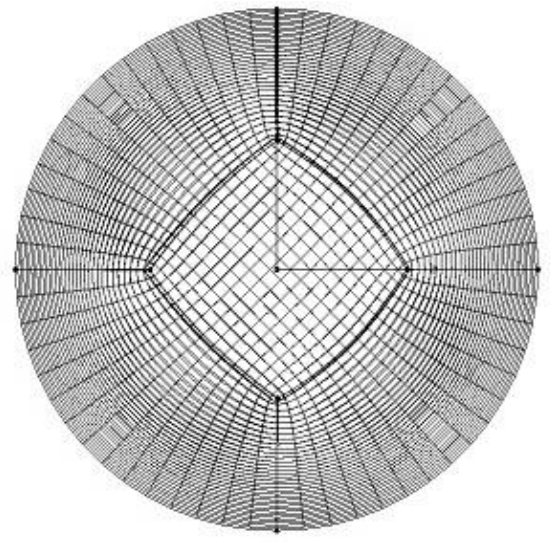

(b)

Fig. 11. Meshing views (a) A micro pipe 3D mesh and it's (b) Front view

The formulas used for convective heat transfer equations at mixed boundary conditions of constant heat flux and constant wall temperature are discussed as follows.

The $\mathrm{q}_{\mathrm{w}}$ is constant wall heat flux at the bottom surface with $100 \mathrm{~W} / \mathrm{cm}^{2}$ and, we compute values of $T_{w}$ at the bottom surface and the mean temperature, $T_{m}\left(T_{m}\right)_{c P}$ and $\left(T_{m}\right)_{v p}$ for constant property (CP) and variable property flows (CP) separately from the Fluent CFD post package. Next, the Nusselt number at CP and VP flows are calculated using Eq. (10) and Eq. (11).

The Nusselt number at CP and VP flows with upper half wall constant wall temperature (CWT) equal to $\left(T_{w}\right)_{C P}=\left(T_{w}\right)$ vp $=373.15 \mathrm{~K}$ and taking are calculated by Eq. (12) and Eq. (13). The mean temperature, $\left(T_{m}\right)_{C p}$ and $\left(T_{m}\right)_{v p}$ are calculated from the Fluent CFD post package in below equations. Here, $q_{w}$ increases from pipe inlet to outlet at the upper half surface. It is calculated at different locations along the centerline of the upper semi-cylindrical wall from the Fluent CFD post package.

$$
\begin{aligned}
& \left\{N u_{C P}\right\} C W T=\frac{h D}{k_{C P}}=\frac{q_{w} D}{k_{C P}\left(T_{w}-T_{m}\right)_{C P}} \\
& \left\{N u_{V P}\right\} C W T=\frac{h D}{k_{V P}}=\frac{q_{w} D}{k_{V P}\left(T_{w}-T_{m}\right)_{V P}}
\end{aligned}
$$

For the mixed boundary condition of CHF and CWT we take the weights and calculate Nu as follows. From theory, the $\mathrm{Nu}=4.36$ is taken for hydrodynamic and thermally developed flow for $\mathrm{CHF}$ and the $\mathrm{Nu}=3.66$ is taken for hydrodynamic and thermally developed flow for CWT and their weights are calculated as, $\mathrm{CHF}=4.36 /(4.36+3.66)=54.4 \%$, which gives weight for $\mathrm{CHF}_{\mathrm{wt}}=0.544$ and therefore weight for $\mathrm{CWT}_{\mathrm{wt}}=(1-0.544)=0.456$. Therefore, the Nusselt number for mixed wall boundary condition as shown in Figure 8 for CP flows is given by,

$$
\left\{N u_{C P}\right\}(C H F+C W T)=C H F_{w t} x\left\{N u_{C P}\right\} C H F+C W T_{w t}\left\{N u_{C P}\right\} C W T
$$

Similarly, the Nu for mixed wall boundary condition for VP flows is given by,

$$
\left\{N u_{V P}\right\}(C H F+C W T)=C H F_{w t}\left\{N u_{V P}\right\} C H F+C W T_{w t}\left\{N u_{V P}\right\} C W T
$$

Figure 12(a) shows the variation of bulk mean temperature $\left(T_{m}\right)$ and micro-pipe wall temperature $\left(T_{w}\right)$ along the flow direction. The driving temperature difference for constant properties (CP) is higher than the variable properties (VP) under the specialized boundary conditions acting on pipe upper and lower halves. Figure 12(b) shows the variation of the Nusselt number along with the 
dimensionless distance of the micro-pipe. The influence of variable properties (thermo-physical) on heat transfer is being captured more accurately. We mean to say that the calculations of the Nusselt number based on the constant properties (CP) have shown to under (lower) prediction of heat transfer. This implies that the design of micro-pipes using variable properties (VP) is a safer design under the special boundary conditions of constant heat flux on one half and constant wall temperature on the other half of micro pipe walls.

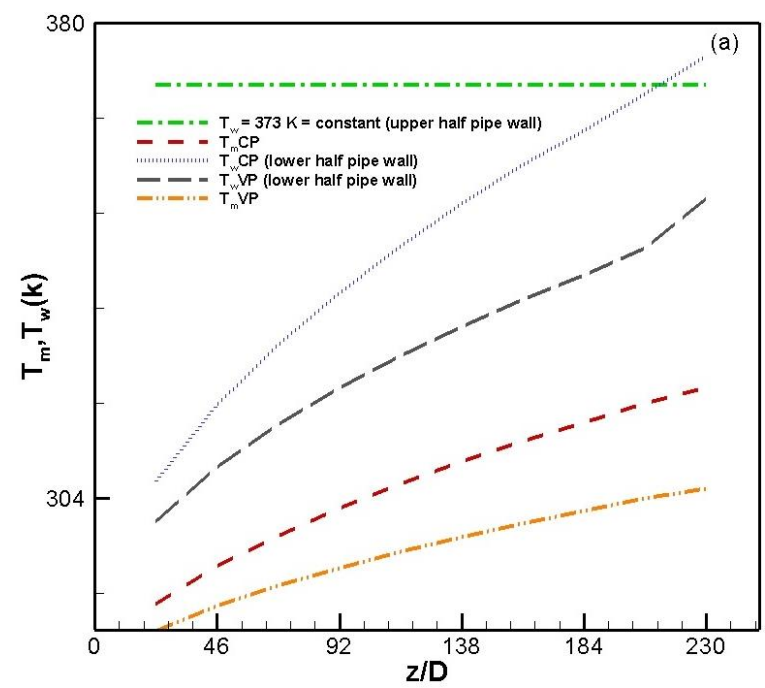

(a)

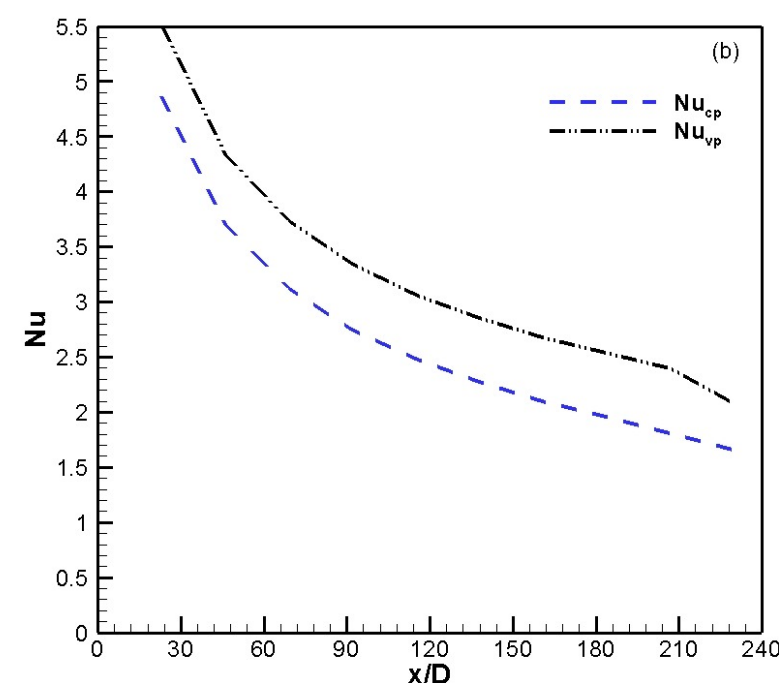

(b)

Fig. 12. Variation of computed (a) mean temperature $T_{m}$ and wall temperature $T_{w}$ and (b) Nusselt number with constant properties CP and variable properties VP for flow in a 3D pipe with an inlet velocity of $3 \mathrm{~ms}^{-1}$ with mixed boundary conditions: at constant wall temperature of $313.15 \mathrm{~K}$ (top half-pipe surface) and constant wall heat flux of $100 \mathrm{~W} / \mathrm{cm}^{2}$ at the bottom half surface pipe

\section{Conclusions}

The CFD analysis is performed on the water flowing through the 2D conventional pipe subjected to constant wall heat flux $\mathrm{BC}$ and $3 \mathrm{D}$ micro-pipe with mixed constant wall temperature and constant heat flux BC. The study concludes that:

i. The 2D pipe flow CFD results of the Nusselt number matches the experimental data. The Nusselt number does not alter whereas the skin-friction decreases, and the pressure drop increases with an increase in inlet Reynolds number. Though there are differences in the variation of system-dependent parameters $T_{m}$ and $T_{w}$ along the length of pipe for $C P$ and VP flows. The variation of system-independent parameters Nu with Re does not vary because of fewer gradients near the wall for the conventional pipe.

ii. The understanding of the influence of variable properties (VP) on heat transfer enhancement in micro-pipe geometry is significant and this will aid us for efficient, safer designs of micropipes under specialized boundary conditions of both constant wall temperature and constant heat flux operating simultaneously.

The effect of inlet Reynolds number (Re) on Nusselt number $(\mathrm{Nu})$ and friction factor will be studied for these fluid flows in the future.

\section{Acknowledgment}

We would like to thank the high-performance center staff for providing us the Aziz supercomputing facility to perform the numerical simulations. (http.//hpc.kau.edu.sa). 


\section{References}

[1] Gulhane, Nitin P., and Shripad P. Mahulikar. "Numerical study of microconvective water-flow characteristics with variations in properties." Nanoscale and Microscale Thermophysical Engineering 15, no. 1 (2011): 28-47. https://doi.org/10.1080/15567265.2010.549928

[2] Mala, G. Mohiuddin, Dongqing Li, and J. D. Dale. "Heat transfer and fluid flow in microchannels." International Journal of Heat and Mass Transfer 40, no. 13 (1997): 3079-3088. https://doi.org/10.1016/S0017-9310(96)00356-0

[3] Sobhan, Choondal B., and Suresh V. Garimella. "A comparative analysis of studies on heat transfer and fluid flow in microchannels." Microscale Thermophysical Engineering 5, no. $4 \quad$ (2001): $293-311$. https://doi.org/10.1080/10893950152646759

[4] Morini, Gian Luca. "Single-phase convective heat transfer in microchannels: a review of experimental results." International Journal of Thermal Sciences 43, no. 7 (2004): $631-651$. https://doi.org/10.1016/i.ijthermalsci.2004.01.003

[5] Hetsroni, G., A. Mosyak, E. Pogrebnyak, and L. P. Yarin. "Fluid flow in micro-channels." International Journal of Heat and Mass Transfer 48, no. 10 (2005): 1982-1998. https://doi.org/10.1016/i.ijheatmasstransfer.2004.12.019

[6] Kandlikar, S. G., and M. E. Steinke. "Single-phase liquid friction factors in microchannel." International Journal of Thermal Sciences 45 (2006): 1073-1083. https://doi.org/10.1016/i.ijthermalsci.2006.01.016

[7] Hong, Chungpyo, and Yutaka Asako. "Heat transfer characteristics of gaseous flows in a micro-channel and a microtube with constant wall temperature." Numerical Heat Transfer, Part A: Applications 52, no. 3 (2007): 219 238. https://doi.org/10.1080/10407780601149847

[8] van Rij, Jennifer, Tim Ameel, and Todd Harman. "Constant wall temperature Nusselt and Poiseuille numbers in rectangular microchannels." In Heat Transfer Summer Conference, vol. 42746, pp. 893-900. 2007. https://doi.org/10.1115/HT2007-32465

[9] Kandlikar, Satish G. "History, advances, and challenges in liquid flow and flow boiling heat transfer in microchannels: a critical review." Journal of Heat Transfer 134, no. 3 (2012). https://doi.org/10.1115/1.4005126

[10] Garimella, Suresh V., and Choondal B. Sobhan. "Transport in microchannels-a critical review." Annual Review of Heat Transfer 13 (2003): 1-50. https://doi.org/10.1615/AnnualRevHeatTransfer.v13.30

[11] Prabhu, Sharad V., and Shripad P. Mahulikar. "Effects of density and thermal conductivity variations on entropy generation in gas micro-flows." International Journal of Heat and Mass Transfer 79 (2014): $472-485$. https://doi.org/10.1016/j.ijheatmasstransfer.2014.07.062

[12] Adham, Ahmed Mohammed, Normah Mohd-Ghazali, and Robiah Ahmad. "Thermal and hydrodynamic analysis of microchannel heat sinks: A review." Renewable and Sustainable Energy Reviews 21 (2013): 614-622. https://doi.org/10.1016/i.rser.2013.01.022

[13] Dixit, Tisha, and Indranil Ghosh. "Review of micro-and mini-channel heat sinks and heat exchangers for single phase fluids." Renewable and Sustainable Energy Reviews $41 \quad$ (2015): $1298-1311$. https://doi.org/10.1016/i.rser.2014.09.024

[14] Rastogi, Pallavi, and Shripad P. Mahulikar. "Geometry-based entropy generation minimization in laminar internal convective micro-flow." Journal of Non-Equilibrium Thermodynamics 44, no. 1 (2019): 81-90. https://doi.org/10.1515/jnet-2018-0036

[15] Tharkar, Ankush D., and Shripad P. Mahulikar. "Size effect on thermal characteristic of tubular heat exchanger at miniscale and microscale." Journal of Thermal Science and Engineering Applications 11, no. 2 (2019). https://doi.org/10.1115/1.4041492

[16] Tharkar, Ankush D., and Shripad P. Mahulikar. "The volume-based properties for dimensional analysis of micro heat exchanger." Journal of Thermal Analysis and Calorimetry 139, no. 5 (2020): 3263-3272. https://doi.org/10.1007/s10973-019-08707-6

[17] Kumar, Krishan, Rajan Kumar, and Rabinder Singh Bharj. "Circular Microchannel Heat Sink Optimization Using Entropy Generation Minimization Method." Journal of Non-Equilibrium Thermodynamics 45, no. 4 (2020): $333-342$. https://doi.org/10.1515/inet-2019-0086

[18] Japar, Wan Mohd Arif Aziz, Nor Azwadi Che Sidik, Natrah Kamaruzaman, Yutaka Asako, and Nura Mu'az Muhammad. "Hydrothermal performance in the Hydrodynamic Entrance Region of Rectangular Microchannel Heat Sink." Journal of Advanced Research in Numerical Heat Transfer 1, no. 1 (2020): 22-31.

[19] Japar, Wan Mohd Arif Aziz, Nor Azwadi Che Sidik, Rahman Saidur, Natrah Kamaruzaman, Yutaka Asako, and Siti Nurul Akmal Yusof. "The effect of triangular cavity shape on the hybrid microchannel heat sink performance." CFD Letters 12, no. 9 (2020): 1-14. https://doi.org/10.37934/cfdl.12.9.114

[20] Nishio, Shigefumi. "Attempts to apply micro heat transfer to thermal management." Heat Transfer and Transport Phenomena in Microscale (2000). 
[21] Reyes, Darwin R., Dimitri lossifidis, Pierre-Alain Auroux, and Andreas Manz. "Micro total analysis systems. 1. Introduction, theory, and technology." Analytical Chemistry 74, no. 12 (2002): 2623-2636. https://doi.org/10.1021/ac0202435

[22] Lee, Junghoon, H. Moon, J. Fowler, Chang-Jin Kim, and T. Schoellhammer. "Addressable micro liquid handling by electric control of surface tension." In Technical Digest. MEMS 2001. 14th IEEE International Conference on Micro Electro Mechanical Systems (Cat. No. 01CH37090), pp. 499-502. IEEE, 2001.

[23] Weilin, Qu, Gh Mohiuddin Mala, and Li Dongqing. "Pressure-driven water flows in trapezoidal silicon microchannels." International Journal of Heat and Mass Transfer 43, no. 3 (2000): $353-364$. https://doi.org/10.1016/S0017-9310(99)00148-9

[24] Mahmoud, Mohamed M., and Tassos G. Karayiannis. "Heat transfer correlation for flow boiling in small to micro tubes." International Journal of Heat and Mass Transfer 66 (2013): 553-574. https://doi.org/10.1016/i.ijheatmasstransfer.2013.07.042

[25] Tuckerman, David B., and Roger Fabian W. Pease. "High-performance heat sinking for VLSI." IEEE Electron Device Letters 2, no. 5 (1981): 126-129. https://doi.org/10.1109/EDL.1981.25367

[26] Dirker, Jaco, Josua P. Meyer, and Darshik V. Garach. "Inlet flow effects in micro-channels in the laminar and transitional regimes on single-phase heat transfer coefficients and friction factors." International Journal of Heat and Mass Transfer 77 (2014): 612-626. https://doi.org/10.1016/i.ijheatmasstransfer.2014.05.048

[27] Asadi, Masoud, Gongnan Xie, and Bengt Sunden. "A review of heat transfer and pressure drop characteristics of single and two-phase microchannels." International Journal of Heat and Mass Transfer 79 (2014): 34-53. https://doi.org/10.1016/j.ijheatmasstransfer.2014.07.090

[28] Kohl, M. J., S. I. Abdel-Khalik, S. M. Jeter, and D. L. Sadowski. "An experimental investigation of microchannel flow with internal pressure measurements." International Journal of Heat and Mass Transfer 48, no. 8 (2005): 15181533. https://doi.org/10.1016/i.ijheatmasstransfer.2004.10.030

[29] Liu, Dong, and Suresh V. Garimella. "Flow Boiling Heat Transfer in Microchannels." Journal of Heat Transfer 129 (2007): 1321-1332. https://doi.org/10.1115/1.2754944

[30] Gulhane, Nitin P., and Shripad P. Mahulikar. "Numerical study of compressible convective heat transfer with variations in all fluid properties." International Journal of Thermal Sciences 49, no. 5 (2010): 786-796. https://doi.org/10.1016/i.ijthermalsci.2009.11.001

[31] Herwig, Heinz, and Shripad P. Mahulikar. "Variable property effects in single-phase incompressible flows through microchannels." International Journal of Thermal Sciences 45, no. 10 (2006): 977-981. https://doi.org/10.1016/j.ijthermalsci.2006.01.002

[32] Ozalp, A. Alper. "Combined effects of pipe diameter, Reynolds number and wall heat flux and on flow, heat transfer and second-law characteristics of laminar-transitional micro-pipe flows." Entropy 12, no. 3 (2010): $445-472$. https://doi.org/10.3390/e12030445

[33] Pasha, Amjad Ali, A. Mushtaq, and Khalid A. Juhany. "Numerical study of heat transfer of water flow through pipe with property variations." Athens Journal of Technology and Engineering 4, no. 4 (2017): 359-385. https://doi.org/10.30958/ajte.4-4-4

[34] Pasha, Amjad Ali, M. Abdul Raheem, N. Islam, K. A. Juhany, A. Mushtaq, and S. S. Halkarni. "CFD Study of Variable Property Effects on Laminar Micro-convective Heat Transfer." Arabian Journal for Science \& Engineering (Springer Science \& Business Media BV) 44, no. 6 (2019). https://doi.org/10.1007/s13369-019-03797-8

[35] Heyhat, M. M., F. Kowsary, A. M. Rashidi, M. H. Momenpour, and A. Amrollahi. "Experimental investigation of laminar convective heat transfer and pressure drop of water-based Al2O3 nanofluids in fully developed flow regime." Experimental Thermal and Fluid Science $44 \quad$ (2013): $483-489$. https://doi.org/10.1016/j.expthermflusci.2012.08.009

[36] Rohsenow, Warren M., James P. Hartnett, and Young I. Cho. Handbook of heat transfer. Vol. 3. New York: McGrawHill, 1998.

[37] Holman, J. P. Heat Transfer. McGraw-Hill Education, 2009. 